\title{
A Generalized Definition of Quantifier Absorption
}

\author{
Nissim Francez \\ Technion, Haifa
}

\author{
Yoad Winter \\ OTS, Utrecht University
}

\section{Introduction}

In most artificial logical languages with quantifier operators variable binding operates in one, constant direction, normally from left to right. Natural languages, on the other hand, provide a rather infrequent construction which can be interpreted as binding in the opposite direction: a quantifier binds a variable that linearly precedes it in the sentence. A famous example for "backward binding" is the case of Bach-Peters' sentences. For instance:

(1) [ Every pilot who saw $\left.\underline{i t}_{2}\right]_{1}$ hit $[\underline{\text { some mig that chased him }}]_{2}$

In one reading under a quite subtle judgement, which is widely accepted in the literature, the relation between the underlined NP's in (1) can be considered, intuitively speaking, as a case where a variable, the translation of $i$, is bound by a quantifier, the translation of some mig that chased him. If this judgement is correct, as many speakers seem to agree, then this is a case where a quantified NP "binds backward" a pronoun that linearly precedes it, a peculiar case of anaphora that is sometimes called cataphora. The interest in this phenomenon emerged from the inter-relations between the cataphoric link and the forward anaphoric link between the NP's which are co-indexed by 2 in (1). The basic puzzle Bach-Peters' sentences evoke is this: how can the subject bind the pronoun in the object, while the object at the same time binds the pronoun in the subject?

In this paper we follow the proposal in Higginbotham \& May's paper "Questions, Quantifiers and Crossing" (1981) to define an operation of quantifier absorption that allows simultaneous binding of two positions by a polyadic quantifier. We will show some problems for Higginbotham \& May's original procedure and propose a generalization of their mechanism that allows a correct treatment of BachPeters' sentences with certain plural objects, a more explicit indexing procedure and a connection between BP sentences and other cases of cataphoric binding.

\section{Higginbotham \& May's proposal}

Higginbotham \& May (henceforth H\&M) propose a mechanism that generates at LF an "absorbed" NP that binds two trace positions. Schematically, syntactic absorption generates one NP from two standardly adjoined NP's at LF. This syntactic operation is illustrated in (2) below.

(2) Syntactic Absorption: $\quad \ldots\left[\mathrm{NP}_{i}\left[\mathrm{NP}_{j} \ldots \rightarrow \ldots\left[\mathrm{NP}_{i} \mathrm{NP}_{j}\right]_{i, j} \ldots\right.\right.$ 


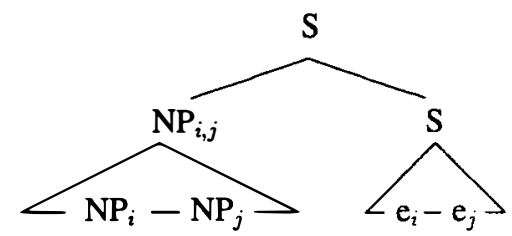

Sentence (1) gets the LF in (3).

(3) [[ every pilot who saw it $\left.]_{1}[\text { some mig that chased him }]_{2}\right]_{1,2}\left[e_{1}\right.$ hit $\left.e_{2}\right]$

How is (3) interpreted? The natural extension in generalized quantifier theory that is needed to allow that is the definition of polyadic determiners, as given in (4).

(4) A polyadic determiner: For $n$ positive natural numbers $i_{1}, i_{2}, \ldots i_{n}$, a determiner of signature $\left\langle i_{1}, i_{2}, \ldots i_{n}\right\rangle$ over the domain $E$ is a function $\operatorname{Pow}\left(E^{i_{1}}\right) \times \operatorname{Pow}\left(E^{i_{2}}\right) \times \ldots \times \operatorname{Pow}\left(E^{i_{n}}\right) \rightarrow\{0,1\}$

There are two stages in H\&M's interpretation of (3) using polyadic quantification:

1. Generate two relations for the restriction and the scope of a $\langle 2,2\rangle$ determiner. The scope $S$ is simply the relation hit'. For the restriction $R$-intersect the relations in the absorbed NP:

$$
\begin{aligned}
& A=\llbracket \text { pilot who saw it } \rrbracket=\left\{\langle x, y\rangle \mid \operatorname{pilot}^{\prime}(x) \wedge \mathbf{s e e}^{\prime}(x, y)\right\} \\
& B=\llbracket \text { mig that chased him }=\left\{\langle x, y\rangle \mid \mathbf{m i g}^{\prime}(y) \wedge \text { chase }^{\prime}(y, x)\right\} \\
& R=A \cap B=\left\{\langle x, y\rangle \mid \operatorname{pilot}^{\prime}(x) \wedge \operatorname{see}^{\prime}(x, y) \wedge \operatorname{mig}^{\prime}(y) \wedge \operatorname{chase}^{\prime}(y, x)\right\}
\end{aligned}
$$

2. Absorb the determiners every' and some' into every'-some' according to definition (5) below and apply:

$$
\begin{aligned}
& \text { every'-some }^{\prime}(R, S) \Leftrightarrow \\
& \text { every }^{\prime}\left(\operatorname{dom} R,\left\{x \mid \operatorname{some}^{\prime}\left(R_{x}, S_{x}\right)\right\}\right) \Leftrightarrow \\
& \forall x\left[\exists y\left(\operatorname{pilot}^{\prime}(x) \wedge \operatorname{see}^{\prime}(x, y) \wedge \operatorname{mig}^{\prime}(y) \wedge \operatorname{chase}^{\prime}(y, x)\right) \rightarrow\right. \\
& \left.\quad \exists y\left(\operatorname{pilot}^{\prime}(x) \wedge \operatorname{see}^{\prime}(x, y) \wedge \operatorname{mig}^{\prime}(y) \wedge \operatorname{chase}^{\prime}(y, x) \wedge \operatorname{hit}^{\prime}(x, y)\right)\right]
\end{aligned}
$$

Definition (5) is the general mechanism in H\&M's system designed to obtain the correct interpretation of BP sentences. Let us call this mechanism determiner absorption.

(5) Higginbotham and May's determiner absorption: For any two determiners $D_{1}$ and $D_{2}$ of signature $\langle 1,1\rangle$ the absorbed determiner $\mathbf{D}_{1}-\mathbf{D}_{2}$ is of signature $\langle 2,2\rangle$ and is defined by:

$\mathbf{D}_{1}-\mathbf{D}_{2}(R, S)=\mathbf{D}_{1}\left(\operatorname{dom} R,\left\{x \mid \mathbf{D}_{2}\left(R_{x}, S_{x}\right)\right\}\right)$

Recall that for any binary relation $R$ :

$\operatorname{dom} R=\{x \in E \mid \exists y R(x, y)\}$

$R_{a}=\{y \in E \mid R(a, y)\}$ 


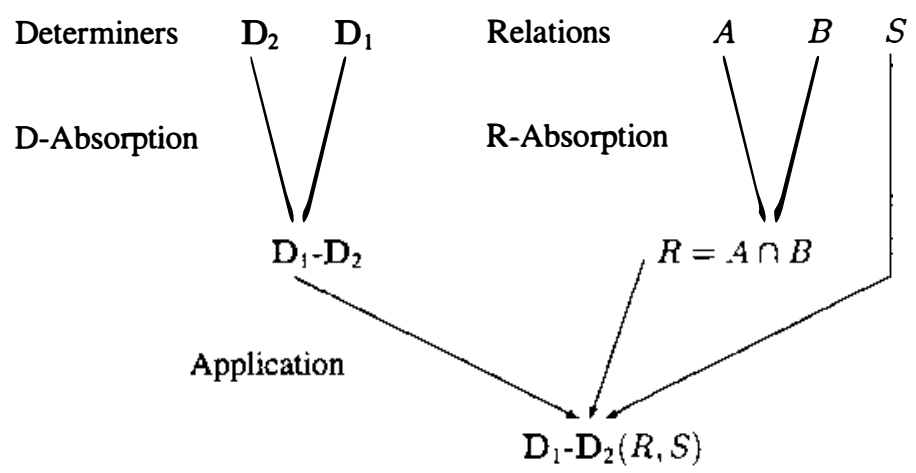

Figure 1: Higginbotham and May's procedure of absorption

H\&M's procedure is summarized in figure 1.

In addition to the correct treatment of (1), one might expect the absorption procedure to capture correctly the truth conditions of all BP sentences. Also, to obtain some generality, we would like absorption to be more than a constructionspecific rule for BP sentences. Another technical improvement needed in H\&M's procedure is an explicit formulation of the indexing strategy assumed. In the next section we discuss these issues.

\section{Towards a more general procedure}

Consider the following variation on (3), with a plural indefinite object in the matrix sentence.

(6) [ Every pilot who saw them $]_{1}$ hit [ two migs that chased him $]_{2}$

The treatment of (6) using H\&M's analysis is as follows:

$$
\begin{aligned}
& \text { every'-two' }(R, S) \Leftrightarrow \\
& \text { every }^{\prime}\left(\operatorname{dom} R,\left\{x \mid \mathbf{t w o}^{\prime}\left(R_{x}, S_{x}\right)\right\}\right) \Leftrightarrow \\
& \forall x\left[\exists y\left(\operatorname{pilot}^{\prime}(x) \wedge \operatorname{see}^{\prime}(x, y) \wedge \operatorname{mig}^{\prime}(y) \wedge \operatorname{chase}^{\prime}(y, x)\right) \rightarrow\right. \\
& \left.\quad \exists 2 y\left(\operatorname{pilot}^{\prime}(x) \wedge \operatorname{see}^{\prime}(x, y) \wedge \dot{m i g}^{\prime}(y) \wedge \operatorname{chase}^{\prime}(y, x) \wedge \operatorname{hit}^{\prime}(x, y)\right)\right]
\end{aligned}
$$

This is an unacceptable reading. It can be paraphrased by:

(7) Every pilot who saw some mig that chased him hit two migs that chased him and that he saw.

whereas the more plausible reading of $(6)$ is:

(8) Every pilot who saw two migs that chased him hit two migs that chased him and that he saw. 
Plausibly, the universal quantification in (6) is over pilots who saw (at least) two migs, and not less than that, as in H\&M's definition. The origin of this problem is that in H\&M's definition (5) the determiner $D_{1}$ in the absorbed determiner quantifies over the set $\operatorname{dom} R=\operatorname{dom}(A \cap B)$ and this results in automatic existential quantification as observed in (7), with no respect to the determiner $\mathbf{D}_{2}$.

Our proposal is to eliminate the procedure of R-absorption in H\&M's mechanism (the generation of $R$ by intersecting $A$ and $B$ ) and define $\mathrm{D}$-absorption to generate a determiner of signature $\langle 2,2,2\rangle$ as defined in (9) below.

(9) Revised determiner absorption: For any two determiners $D_{1}$ and $D_{2}$ of signature $\langle 1,1\rangle$ the absorbed determiner $\mathbf{D}_{1}-\mathbf{D}_{2}$ is of signature $\langle 2,2,2\rangle$ and is defined by:

$$
\mathbf{D}_{1}-\mathbf{D}_{2}(A, B, S)=\mathbf{D}_{1}\left(\left\{x \mid \mathbf{D}_{2}\left(B_{x}, A_{x}\right)\right\},\left\{x \mid \mathbf{D}_{2}\left((A \cap B)_{x}, S_{x}\right)\right\}\right)
$$

Using this definition the absorbed determiner can apply directly to the relations $A, B$ and $S$. Sentence (6) is then analyzed as follows.

$$
\begin{aligned}
& \operatorname{every}^{\prime}-\operatorname{two}^{\prime}(A, B, S) \Leftrightarrow \\
& \text { every }^{\prime}\left(\left\{x \mid \mathbf{t w o}^{\prime}\left(B_{x}, A_{x}\right)\right\},\left\{x \mid \mathbf{t w o}^{\prime}\left((A \cap B)_{x}, S_{x}\right)\right\}\right) \Leftrightarrow \\
& \forall x\left[\exists 2 y\left(\operatorname{pilot}^{\prime}(x) \wedge \operatorname{see}^{\prime}(x, y) \wedge \operatorname{mig}^{\prime}(y) \wedge \operatorname{chase}^{\prime}(y, x)\right) \rightarrow\right. \\
& \left.\quad \exists 2 y\left(\operatorname{pilot}^{\prime}(x) \wedge \operatorname{see}^{\prime}(x, y) \wedge \operatorname{mig}^{\prime}(y) \wedge \operatorname{chase}^{\prime}(y, x) \wedge \operatorname{hit}^{\prime}(x, y)\right)\right]
\end{aligned}
$$

This formula correctly reflects the paraphrase in (8).

An independent question is how to determine the indexing of the arguments of an absorbed determiner. For example, why is the relation standing for mig that chased him in (1) $B$ and not $B^{\prime}$ below?

$$
B^{\prime}=\left\{\langle y, x\rangle \mid \operatorname{mig}^{\prime}(y) \wedge \operatorname{chase}^{\prime}(y, x)\right\}
$$

In H\&M's procedure there is no elimination of an analysis using the "inverse relation" $B^{\prime}$ instead of $B$, which would cause an incorrect derivation. We propose a process of index unification within the absorption procedure that keeps track of the order of the arguments in the restriction according to the scope indexing.

For example, in (1) the relevant possible relations are:

$$
\begin{aligned}
& S_{(1.2)}=\left\{\langle x, y\rangle \mid \operatorname{hit}^{\prime}(x, y)\right\} \\
& A_{(1.2)}=\left\{\langle x, y\rangle \mid \operatorname{pilot}^{\prime}(x) \wedge \operatorname{sed}^{\prime}(x, y)\right\} \\
& A_{(2,1)}=\left\{\langle y, x\rangle \mid \operatorname{pilot}^{\prime}(x) \wedge \operatorname{see}^{\prime}(x, y)\right\} \\
& B_{(1.2)}=\left\{\langle x, y\rangle \mid \operatorname{mig}^{\prime}(y) \wedge \operatorname{chase}^{\prime}(y, x)\right\} \\
& B_{(2.1)}=\left\{\langle y, x\rangle \mid \operatorname{mig}^{\prime}(y) \wedge \operatorname{chase}^{\prime}(y, x)\right\}
\end{aligned}
$$


That is, relations like $B^{\prime}\left(=B_{(2,1)}\right)$ are a possibility to be considered. But this possibility is to be eliminated because the only matching of indexing is between $S_{(1,2)}, A_{(1,2)}$ and $B_{(1,2)}$, which are exactly the relations we need (and H\&M use).

This unification procedure can allow us a somewhat better understanding of non-BP sentences with backward quantification. For example:

(10) [ Every pilot who saw them $\left.]_{2}\right]_{1}$ hit [ two migs $]_{2} \quad{ }^{1}$

This sentence has a reading that can be paraphrased by:

(10') Every pilot who saw two migs hit two migs that he saw.

A revised absorption procedure that applies unification also to the arity of the predicates involved can derive this reading in the following way:

1. Basic indexed predicates:

$$
\begin{aligned}
& A_{(1,2)}=\left\{\langle x, y\rangle \mid \operatorname{pilot}^{\prime}(x) \wedge \operatorname{see}^{\prime}(x, y)\right\} \\
& B_{(2)}=\left\{y \mid \operatorname{mig}^{\prime}(y)\right\} \\
& S_{(1,2)}=\left\{\langle x, y\rangle \mid \operatorname{hit}^{\prime}(x, y)\right\}
\end{aligned}
$$

2. Unification of arities to 2 . Two possibilities:

a. $B_{(2)} \rightarrow B_{(2)} \times E_{(i)}=B_{(2, i)}$

b. $B_{(2)} \rightarrow E_{(i)} \times B_{(2)}=B_{(i, 2)}$

3. Index unification forces $B_{(1.2)}(i=1)$.

4. Absorption in the ordinary BP way for the derived $A=A_{(1.2)}, B=B_{(1.2)}$, $S=S_{(1.2)}$ :

$$
\begin{aligned}
& \text { every'-two' }^{\prime}(A, B, S) \Leftrightarrow \\
& \text { every' }\left(\left\{x \mid \mathbf{t w o}\left(B_{x}, A_{x}\right)\right\},\left\{x \mid \mathbf{t w o}^{\prime}\left((A \cap B)_{x}, S_{x}\right)\right\}\right) \Leftrightarrow \\
& \forall x\left[( \boldsymbol { p i l o t } ^ { \prime } ( x ) \wedge \exists 2 y ( \mathbf { m i g } ^ { \prime } ( y ) \wedge \mathbf { s e e } ^ { \prime } ( x , y ) ) ) \rightarrow \exists 2 y \left(\mathbf{s e e}^{\prime}(x, y) \wedge \operatorname{mig}^{\prime}(y)\right.\right. \\
& \left.\left.\quad \wedge \operatorname{hit}^{\prime}(x, y)\right)\right]
\end{aligned}
$$

This reflects the reading (10').

Summary: We have proposed a revision in H\&M's mechanism that (i) gives a correct analysis of more BP sentences, (ii) is more explicit about the indexing unification procedure and (iii) accounts for other cases of cataphoric quantification besides BP sentences. The proposed modification is illustrated in figure 2 .

\section{Endnotes}

* The part of the first author was partly funded by a grant from the Israeli Ministry of Science and by the fund for the promotion of research in the Technion.

1. Note that the cataphoric reading of this sentence is related to the plurality of the object. A sentence like every pilot who saw it $t_{1}$ hit somemig ${ }_{1}$ shows a weak crossover effect. See Winter \& Francez (1994) for more discussion of non-BP cataphora. 


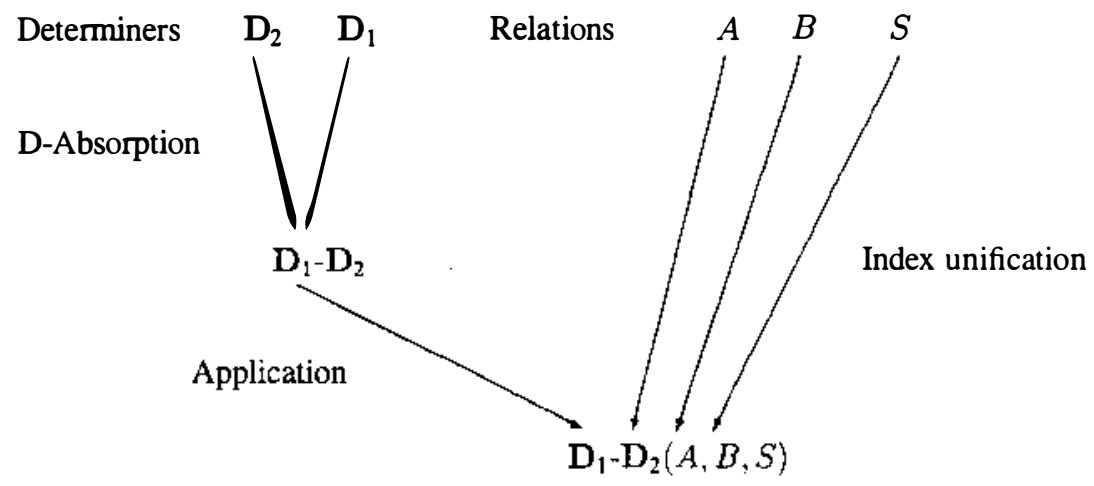

Figure 2: A revised procedure of absorption

\section{References}

Higginbotham, J., and R. May (1981), "Questions, quantifiers and crossing”, Linguistic Review 1: 41-79.

Winter, Y., and N. Francez, "Cataphoric quantification and generalized quantifier absorption", technical report \#LCL 94-3, Technion, computer science department.

Nissim Francez

Computer Science Department

Technion

Haifa 32000

Israel

francez@cs.technion.ac.il
Yoad Winter

OTS, Utrecht University

Trans 10

3512 JK Utrecht

The Netherlands

yoad.winter@let.ruu.nl 